\title{
Welfare effects of open access competition on railway markets
}

Emanuel Broman and Jonas Eliasson

The self-archived postprint version of this journal article is available at Linköping University Institutional Repository (DiVA):

http://urn.kb.se/resolve?urn=urn:nbn:se:liu:diva-161377

N.B.: When citing this work, cite the original publication.

Broman, E., Eliasson, J., (2019), Welfare effects of open access competition on railway markets, Transportation Research Part A, 129, 72-91. https://doi.org/10.1016/j.tra.2019.07.005

Original publication available at:

https://doi.org/10.1016/j.tra.2019.07.005

Copyright: Elsevier

http://www.elsevier.com/

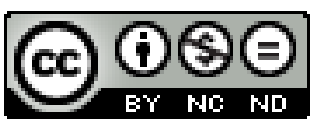




\title{
Welfare effects of open access competition on railway markets
}

\author{
Emanuel Broman*12, Jonas Eliasson ${ }^{2}$ \\ ${ }^{1}$ Swedish National Road and Transport Research Institute (VTI), Malvinas väg 6, SE-114 28 Stockholm, Sweden \\ ${ }^{2}$ Linköping University, Luntgatan 2, SE-602 47 Norrköping, Sweden
}

\begin{abstract}
In recent years, several countries have deregulated passenger railway markets to allow open access. The aim is for competition to lower fares and increase quality of service, thereby increasing demand, economic efficiency and overall social welfare. We use a stylised simulation model to study how open access competition affects fares, demand, supply, consumer surplus and operator profits compared to a profit maximising monopoly and to a welfare maximising benchmark situation. We conclude that aggregate social welfare increases substantially when going from profit maximising monopoly to duopoly competition, as consumers make large gains while operators' profits fall. It matters how the infrastructure manager sets the timetable based on operators' capacity requests: the infrastructure manager should strive to increase competition by mixing competing operators' departures as much as possible. According to simulations, there generally exists a stable competitive Nash equilibrium with two or more profitable operators. Although operators are identical in the model setup, the Nash equilibrium outcome is asymmetric: one operator has more departures and higher average fares than the other does. If operators are allowed to cooperate, however, for example by trading or selling departure slots, the equilibrium situation tends to revert to monopoly. The regulatory framework must therefore prevent collusion and facilitate market entry. Even the potential for competitive entry tends to increase social welfare, as the monopolist has incentives to increase supply as an entry deterrence strategy.
\end{abstract}

Keywords: open access; rail; reform; capacity allocation; passenger

\section{Introduction}

Railways should be organised to generate the highest welfare. Historically, governments have tried to achieve this through nationalising both infrastructure and operations, organized in a government-controlled operator striving to maximise societal welfare in some broad sense. More lately, some governments have outsourced operations to private firms to increase the efficiency of service production but retained control over timetables and fares. Although in theory these regimes could achieve maximal welfare, they are hampered by an information gap: unlike profit, welfare cannot be directly observed, and it has proven difficult for supposedly welfare maximising monopolies to set efficient fares and levels of supply. Operators have often come to rely on large and hard-todefend subsidies. Partly for this reason, Alexandersson and Hultén (2008) argue, these operators often became profit maximising instead. This has sometimes been an explicit target and other times a de facto outcome, and it has happened both for government-run services and tendered traffic. The welfare deficiency of a profit maximising regime compared to welfare maximum can be substantial, however. This has prompted a search for alternative ways to organise railway markets.

Open access competition has been introduced in several markets as an alternative to monopoly, first for freight operations and more recently also for passenger services, in expectation of higher welfare outcomes. Competitive markets do indeed tend to generate substantially more welfare compared to profit maximising monopoly regimes, also when - as in this case - there tends to be few active firms (see Appendix A for a standard Cournot model of the duopoly case). But the passenger railway market differs from the standard oligopoly model in three important ways. First, the market is inherently segmented horizontally in time, since no two trains can depart at the same time on the same line. This naturally creates product differentiation and hence "local monopolies" in time with respect to passengers who prefer a certain departure (or arrival) time. Second, since the infrastructure remains in government ownership, the regulator has an important role in setting the precise timetable based on operators' requests for capacity. Third, train operators can set unique fares for each individual departure, dynamically taking into account shifts in demand and prices of competing alternatives through yield management techniques.

A number of questions arise from this. Is there a welfare gain from replacing profit maximising monopoly with competition? Is this result similar in a model specifically built to characterise passenger railway markets, compared

\footnotetext{
* Corresponding author. Tel.: +46 70-237 1924

E-mail address: emanuel.broman@vti.se
} 
to a generic model? Is there a stable equilibrium in terms of fares and numbers of departures? Are outcomes symmetric, given a market with two identical operators? It is common that operators coordinate and negotiate to resolve conflicts between path requests, and "slot trading" is common and sometimes even encouraged. What are the consequences of this for welfare and efficiency? Finally, how should the infrastructure manager set the timetable based on operators' requested departure frequencies? For example, does the order and separation in time of the operators' departures matter?

Our approach to answer these questions is to use a stylised simulation model to explore the dynamics created by the market's most prominent features. Using simulation allows us to study a richer model than can be analysed with purely analytic methods, while the focus on certain key characteristics supports comprehension of the causes for the results of the simulation. Three situations are compared: open access competition, profit maximising monopoly, and a theoretical welfare maximising benchmark. The results are tested to hold for a range of parameter values (see Appendix E). ${ }^{2}$

In the model, two competing operators announce their desired departure frequencies, and the infrastructure manager then decides the order and precise departure times. Conditional on this departure pattern, operators set specific fares for each departure to maximise their total profits, mutually taking each other's fares into account. Frequencies are determined to reach a Nash equilibrium (we also study the Stackelberg equilibrium). The model hence reflects several specific features for the railway market: the infrastructure manager has a certain power to regulate the eventual timetable; competition occurs not only between operators but between departures that are close in time; specific fares can be set for each individual departure by the operator; there is a natural product differentiation in the form of departure times; and passengers have individual preferred departure times (PDTs).

Results indicate that duopoly competition substantially increases aggregate social welfare compared to a profit maximising monopoly, coming close to the welfare maximising benchmark. The consumer surplus increases while profits decrease, due to lower average fares and higher service frequency, and the net welfare effect of this is positive and substantial. These results are analogous to those of a standard Cournot duopoly model without product or price differentiation. However, if profits in the competitive situation are transferred abroad, for example if a national monopoly operator is replaced by foreign-owned operators, replacing the monopoly with competition in fact tends to reduce overall domestic welfare.

With two identical operators, a stable equilibrium is reached, but it is asymmetric in terms of the size of the operators. The equilibrium consists of one dominating operator supplying more departures and higher average fares, and one small operator with fewer departures and lower average fares. ${ }^{3}$ This result arises despite that the model assumes two identical operators and no economies of scale. This differs from the standard Cournot model, and stems from the natural "product differentiation" arising from the fact that train services have different departure times and can be priced individually.

For the equilibrium to hold, both operators of course need to remain in the market. But the combined profit of the competing operators is substantially lower than the monopoly profit, meaning that there is an incentive to merge operations into a single unit, or for one operator to buy the other's departure slots. The regulatory framework hence needs to be constructed in a way that prevents the market from reverting into monopoly. How to do this is not trivial. The activities of operators that share the same tracks must by necessity be coordinated, and there are also practical arguments for letting operators buy and sell the right to run a train at a certain time (a 'slot') in a deregulated market. If coordination processes or slot trading arrangements are naïvely designed, the market is likely to end up with one monopolistic operator, even if there is no formal collusion between operators; operators' business incentives are enough to cause the market to go from oligopoly to monopoly. The design of any capacity allocation process needs to take this problem into account if competition is to be upheld.

A preliminary version of some of the results in this paper were presented in (Broman \& Eliasson, 2017). The present paper contains a refinement of that model, including an updated expression for consumer surplus and a more realistic cost-structure for operators; the latter affects the dynamics of the model. A new benchmark-scenario is included: a monopolist that operates under an entry-deterrence strategy. We also analyse how the infrastructure manager should construct a timetable out of operators' requests, in order to maximise welfare. Additional policy implications are drawn from the refined model and new benchmark case.

\section{Background}

Over the past few decades, many railway markets have become increasingly deregulated, especially in Europe. Most European countries nowadays have separated service provision from infrastructure management, meaning

\footnotetext{
${ }^{2}$ Concession contracts are not modelled explicitly as they share the dynamics of either profit maximising or welfare maximising monopoly, depending on how they are regulated.

${ }^{3}$ Except in trivial cases, such as when both operators only have one departure each.
} 
that one or several operators run the trains, determine fares and (to a large extent) determine service frequencies, while an infrastructure manager (usually a government agency) is responsible for track maintenance and investments, and also for solving possible conflicts between competing operators' service requests. Some operators are companies or agencies controlled by the government, while some operators are privately owned companies. Sweden was among the first countries to deregulate its railway system, separating service operations from infrastructure management in 1989. The UK has also come far in this respect, with public tenders for all lines. In one way or another, the deregulation trend has spread throughout Europe and beyond.

A few countries are now taking this one step further, through introducing competition not just for the tracks but on the tracks - so-called open access competition. Since 2001, the Swedish freight market is completely deregulated, and since 2010 also the passenger market; open access competition is the market regime for all profitable parts of the network (services on unprofitable lines are procured through public tendering) (Alexandersson \& Hultén, 2009). Other countries experimenting with open access competition include Austria, the Czech Republic, Italy and the UK (Beria et al, 2016). The result has in most cases been a duopoly situation ${ }^{4}$, sometimes complemented by smaller niche actors. Our analysis in this paper focuses on passenger markets.

The welfare of railways depends on the details of timetables (Eliasson \& Börjesson, 2014), but it is not clear how these are affected by open access competition. More is known about the effects of open access on other modes than rail. When the British bus market was deregulated in the $1980 \mathrm{~s}$, new entrants challenged the incumbent on a small number of submarkets. Where they did, this led to a short period of fierce competition in price as well as frequency. Profitability for both competitors sank rapidly, and within a year or so one of them closed shop. At that point fares increased again and departure frequencies decreased, although prices remained lower and frequencies higher compared to before deregulation - possibly as a deterrence strategy against competition (Evans, 1990). Simulations of the bus market reach similar conclusions (see e.g. Evans (1987)).

Railway markets differ from bus markets in some important respects, however, which affects outcomes. Whereas prices are set freely, railway timetables are partly determined by the infrastructure manager, which is usually a government agency. Moreover, timetables can usually only be changed at certain points in time, common for all operators. Therefore, the market dynamics can be described by a three-step process: First, operators apply for capacity; then, departure slots are allocated; finally, prices are set in competition, with timetables fixed for a certain time period.

Another difference is that individual departures have different prices, which is unusual in bus markets. In fact, individual railway tickets are often sold at different prices, due to the prevalence of yield management price-setting software. Also partly because of such software, prices can be adapted quickly when needed, possibly removing the reason for a monopolist to lower prices as an entry deterrence strategy. In contrast, deterrence strategies in frequency seem more plausible, as building the necessary capacity is a slower process.

\section{The model}

The simulation model used in this paper is constructed to capture some essential features of open access competition in passenger railway markets. We consider a duopoly with only one origin-destination pair, where all train services have the same running time; they only differ in terms of departure times and fares. ${ }^{5}$ Passengers choose which train service to travel with (if any) by minimising their generalised travel cost, which is the sum of the fare and the schedule delay (the difference between the PDT and the respective service's departure time). Demand is a function of generalised cost.

Operators have identical production cost functions, and strive to maximise profits by choosing departure frequencies and fares. These are determined in a two-stage process. First, operators announce their desired frequencies. The regulator (the infrastructure manager) determines the timetable based on these frequencies, ordering operators' departures to maximise social welfare. Second, operators decide the fares of each departure to maximise their respective total profit under the given timetable, taking the fares of competing operators into account. Fares are hence determined by a Nash equilibrium. Operators are assumed to understand what the outcome of the second step will be from the beginning, and choose frequencies in the first step accordingly. Nash equilibrium is therefore reached in both the first step (frequencies) and the second step (fares).

Through this design, the model captures some key characteristics that distinguish railway markets from that of e.g. buses. The infrastructure manager is by necessity involved in timetabling, and strives to maximise welfare (which is not necessarily aligned with operators' interests). Fares and timetables are determined in a two-step process. The timetable is based on operators' requests, but the details are determined by the infrastructure manager,

\footnotetext{
${ }^{4}$ Preston (2008) cites too thin demand in most markets along with economies of scale and density as reasons to assume that the number of actors in this type of market will be very limited.

${ }^{5}$ The former are also features of a simple Cournot model - see Appendix A - that is used as a benchmark in Section 4.
} 
and lasts for a certain period of time (such as a year). Fares are set conditional on the timetable, can be changed relatively easily, and are set freely by operators. Moreover, fares are allowed to vary between departures, even if they are operated by the same operator. Operators set the fare of each specific departure to maximise profits, taking into account how this affects the profits of all other departure run by the same operator.

\subsection{Calculating demand}

Every potential passenger has a unique $\operatorname{PDT}^{6} t$. The PDTs have a distribution $\varphi(t)$ over the day such that $\int \varphi(t) d t$ equals the daily potential demand. There are $N$ trains departing at times $T_{1}, T_{2}, \ldots, T_{N}$ with corresponding fares $p_{1}, p_{2}, \ldots, p_{N}$. Trains are assumed to have unlimited capacity, and the marginal passenger cost for operators is zero. Passengers choose the departure that minimises their generalised travel cost, which is the sum of the fare and the monetary value of their schedule delay, i.e. the difference between the departure time $T_{n}$ and the PDT $t$. We assume that the monetary value of the schedule delay is constant and symmetric, so the minimal generalised travel cost for a passenger with PDT $t$ is

$$
c(t)=\min _{n}\left(p_{n}+\alpha\left|T_{n}-t\right|\right)
$$

Demand depends linearly on travellers' generalised cost. ${ }^{78}$ The number of passengers with PDT $t$ that choose to travel is

$$
D(t)=\max \{\varphi(t)-\beta c(t), 0\},
$$

where $\beta>0$ is the slope of the demand curve.

To calculate the number of passengers choosing to travel with departure $n$, let $\tau_{n}$ be the PDT of a passenger who is indifferent between departures $n$ and $n+1$. This means that passengers with PDTs in the interval $\left[\tau_{n-1}, \tau_{n}\right]$ will travel with train service $n$. Let $\tau_{0}$ be the start of the day and $\tau_{N}$ the end of the day. Straightforward calculations give

$$
\tau_{n}=\frac{p_{n+1}-p_{n}}{2 \alpha}+\frac{T_{n+1}+T_{n}}{2}, n=1, \ldots, N-1
$$

The number of passengers who travel with train service $n$ is then

$$
D_{n}=\int_{\tau_{n-1}}^{\tau_{n}} D(t) d t
$$

The specific case of constant $\varphi(t)$ is treated in Appendix C.

\subsection{Consumer and producer surplus}

Using equation (2), the consumer surplus conditional on PDT $t$ becomes (the derivations can be found in Appendix B)

$$
C S(t)=\frac{1}{2 \beta} D(t)^{2}=\frac{\left(\varphi-\beta p_{n}\right)^{2}}{2 \beta}+\frac{\alpha^{2} \beta}{2}\left(T_{n}-t\right)^{2}+\alpha\left(\beta p_{n}-\varphi\right)\left|T_{n}-t\right|
$$

Assuming that $\varphi(t)$ is constant throughout the day (which we will do in the simulations) the consumer surplus becomes

$$
C S=\sum_{n} \int_{\tau_{n-1}}^{\tau_{n}} C S(t) d t=
$$

\footnotetext{
${ }^{6}$ Preferred departure time (PDT) may be substituted with preferred arrival time with analogous results.

${ }^{7}$ Demand is thus endogenous. This is compatible with assuming inter-modal or inter-route competition.

${ }^{8}$ Assuming locally linear demand allows us to calculate consumer surplus through the rule of a half.
} 


$$
\begin{gathered}
=\sum_{n} \frac{\left(\varphi-\beta p_{n}\right)^{2}}{2 \beta}\left(\tau_{n+1}-\tau_{n}\right)+\frac{\alpha^{2} \beta}{6}\left(\left(T_{n}-\tau_{n}\right)^{3}+\left(\tau_{n+1}-T_{n}\right)^{3}\right) \\
+\frac{\alpha\left(\beta p_{n}-\varphi\right)}{2}\left(\left(T_{n}-\tau_{n}\right)^{2}+\left(\tau_{n+1}-T_{n}\right)^{2}\right)
\end{gathered}
$$

The profit for each operator is the sum of net profits for all its departures during a day:

$$
\Pi_{k}=\sum_{n \in S_{k}}\left(p_{n} D_{n}(p)-K\right)-\kappa
$$

where $S_{k}$ is the set of train services run by operator $k, K$ is the operations cost per departure and $\kappa$ is the operator's fixed cost. Each operator chooses its fares to maximise $\Pi$, conditional on the fares of the other operator, so that fares are decided by the Nash equilibrium.

The total social welfare is the sum of the consumer surplus and the producer surplus. The model hence does not include any external benefits of traveling. Income effects are not included in the model, allowing us to use a Marshallian welfare measure. The conventional assumption that the producer surplus is included in the overall welfare is not innocuous, since train operators may well be foreign owned and a decision maker in a country may well consider producer surplus accruing to foreign owners as "lost" from a domestic perspective (compared to, say, a government-owned operator, where profits accrue to domestic tax payers). In Section 4.2, we will also discuss how this perspective may change some of the conclusions.

\subsection{Choosing frequencies and fares}

The game is designed to reflect an important aspect of railway markets: that frequencies are set rarely, while fares are set continuously. It therefore constitutes of two stages, which are played simultaneously but depend on each other. This is how it is played:

There are two operators. In the first stage, they decide their respective frequency, i.e. how many departures per day they will run. An equilibrium point is reached where no operator wishes to change its chosen frequency. Then the infrastructure agency decides the exact timetable so that there is equal space between any two consecutive departures, and departures of different operators are intermingled in such a way that passengers have as many options as possible throughout the day. (We will demonstrate that this is the welfare maximising way to arrange the departures, given a uniform PDT distribution.)

In the second stage, operators set fares for each departure. The sub-game ends in Nash equilibrium, where no operator wishes to change the fare on any of its departures given the timetable and the fares of its competitor. The process is reiterated until both the frequency and the price game are in equilibrium. Both operators are assumed to have full knowledge of each other's strategies, of the game's dynamics and of the regulator's strategy.

Note that fares affect demand in two ways: decreasing a fare on a specific departure will both increase the total number of passengers and attract passengers from adjacent departures. We assume that operators take into consideration the ownership of adjacent departures when setting fares. This means that the general price level depends not only on the frequency of departures but also on the how departures are ordered.

\subsection{Parameters}

The purpose of a stylised simulation as the one used here is obviously not to predict quantitative outcomes but to gain insights. Still, the model parameters are calibrated to give outcomes resembling a real case, to ensure that we have sufficient confidence in the relative magnitudes of the results. Moreover, the conclusions reported in the paper have been tested for robustness through parameter sensitivity analysis. Appendix E presents some key results from the main sensitivity analyses.

The model parameters have been calibrated so the outcome resembles the Stockholm-Gothenburg railway line: ca 5,000 daily trips, between 10 and 30 departures per direction, and fares mainly in the interval of 200-1,000 SEK. In the base case, the parameters are scheduling cost $\alpha=500 \mathrm{SEK} /$ hour $^{9}$, demand/price parameter ${ }^{10} \beta=$ -10 , potential demand $\int \varphi(t) \mathrm{dt}=15,000$ passengers/day, fixed cost per departure $K=40,000$ SEK $^{11}$ and fixed

\footnotetext{
9 The scheduling cost $\alpha$ is based on the value of headway in (WSP, 2010), assuming a $25 \%$ ratio of business trips. The same value is used in Swedish CBA guidelines (Trafikverket, 2018).

10 The value of $\beta$ is set to calibrate outcomes.

11 The cost per departure is calculated as $K=\gamma_{1} *$ travel time $+\gamma_{2} *$ travel distance where the parameters $\gamma_{1}$ and $\gamma_{2}$ are taken from (SIKA, 2009). The same values are used in Swedish CBA guidelines (Trafikverket, 2018).
} 
daily cost per operator $\kappa=500,000$ SEK. For simplicity, the PDT distribution $\varphi(t)$ is taken to be a uniform distribution; this is simply to make model outcomes easier to interpret. As will be shown below, this means that the regulator (which strives to maximise social welfare) will space train departures at regular time intervals.

\section{Analysis}

This section presents simulation results. Section 4.1 presents results for monopoly situations, including entry deterrence strategies, which serve as benchmarks to be compared with situations with competing operators. Section 4.2 presents results for two competing operators in Nash equilibrium. Section 4.3 shows that the infrastructure regulator, which decides the order and headway of departures given operators' choice of frequencies, should mix departures of competing operators as much as possible, and spread departures evenly to maximise welfare. Throughout the analyses of competitive situations, we will assume that this is what the regulator does. Section 4.4 shows that operators have incentives to collaborate in ways that are harmful to overall welfare, and explains why opportunities for such behaviour arises.

\subsection{Monopoly}

Consider three monopoly situations: welfare maximisation with a cost recovery constraint (i.e. no operator subsidy), profit maximisation, and entry deterrence. The first, welfare maximisation under cost recovery, will serve as a benchmark for subsequent comparisons ${ }^{12}$; it can be interpreted as a publicly controlled company with perfect information, only serving the interests of society (disregarding any potential problems with public monopolies, e.g. of internal efficiency and lack of information about passenger preferences). The second, profit maximisation, is a standard monopoly situation: the monopolist chooses fares and service frequency to maximise profit.

The third situation, entry deterrence, builds on the assumption that fares can be adapted quickly while frequencies cannot. An incumbent monopolist chooses a frequency high enough to deter a potential competitor from entering the market and, given this frequency, the monopolist is then free to choose profit maximising fares. Both the incumbent and a potential competitor anticipate that if there were two competing operators, fares would instead be set according to the Nash equilibrium. It is often impossible for an incumbent to prevent competitive entry with certainty; instead, it can take measures to make it less profitable and more expensive. Such a strategy has no 'optimum' in the normal sense, so we have instead included one possible strategy that makes competitive entry less desirable. Table 1 shows results from the simulation of the first two situations - welfare maximisation and profit maximisation - and a possible entry deterrence strategy.

Table 1. Monopoly situations

\begin{tabular}{lrrr}
\hline & $\begin{array}{r}\text { Welfare max., no } \\
\text { subsidy }\end{array}$ & Profit max. & $\begin{array}{r}\text { Entry deterrence } \\
\text { (example) }\end{array}$ \\
\hline No. of departures (per day) & 22 & 16 & 25 \\
Average fare (SEK) & 104 & 705 & 720 \\
No. of passengers & 13,300 & 7,100 & 7,200 \\
Consumer surplus (SEK) & $8,840,000$ & $2,430,000$ & $2,570,000$ \\
Producer surplus (SEK) & 0 & $3,800,000$ & $3,680,000$ \\
Total welfare (SEK) & $8,840,000$ & $6,230,000$ & $6,260,000$ \\
\hline
\end{tabular}

Welfare maximisation (without subsidies) leads to 22 departures per day, and an average fare of SEK104, which is just enough to make total profit non-negative. Compared to the profit maximising monopoly, there are six more departures, and the average fare is $85 \%$ lower. Demand is almost doubled and consumer surplus is almost four times larger. Total social welfare is just over $40 \%$ higher, since the gain in consumer surplus is partly offset by a decrease in producer surplus.

In the entry deterrence scenario, the incumbent increases the service frequency to discourage competitors from entering the market by making it difficult or unprofitable. If the number of incumbent departures increases, an entrant would also need a larger number of departures to gain the market share needed to pay for fixed costs. As a larger number of departures requires a larger investment in rolling stock, this makes market entry riskier. If the incumbent runs 16 departures, which is the profit maximising frequency, a prospective entrant would need to run at least three departures to be profitable. If the incumbent increases its frequency to 25 departures, a prospective

\footnotetext{
12 Strict welfare maximisation would lead to negative profits, since the optimal fare is equal to the marginal passenger cost, and hence revenues will not cover fixed operations costs. While subsidised train services are common for intra-regional public transport (commuter trains), it is much less common for long-distance train markets, which is the focus of this paper, so we will not consider this situation.
} 
entrant would instead need to run at least four departures to be profitable, and its highest attainable profit would be reduced by $58 \%$ compared to the scenario where the incumbent runs 16 departures. The incumbent, on the other hand, does not lose much by increasing its frequency from 16 to 25 departures: its total profits only decrease by $3 \%$. This is hence a cheap and reasonably effective deterrence strategy for the incumbent. Social welfare increases by this rise in frequency, but only slightly (less than $0.5 \%$ ), since the incumbent can still charge monopoly fares as long as it is the only operator. As a corollary, we can note that if a regulator wants to reduce the negative effects of a monopoly, it is not a very effective strategy to force the monopolist to increase its frequency, as long as the operator is free so set monopoly fares.

\subsection{Frequency equilibrium under duopoly}

In the duopoly situation, we assume that two operators, A and B, announce how many departures they want to run and then the infrastructure manager translates this into a timetable, as explained in Section 3.3. Given this timetable, operators choose profit maximising fares until they reach a Nash equilibrium. The operators know the outcome of this subgame when they decide their number of departures, and their choices of number of departures also lead to a Nash equilibrium.

Table 2. Net profits (in $k S E K$ per day) of operator A and B for different combinations of departure frequencies. The point 16:0 is the profit maximising frequency under monopoly; the point 18:7 is the Nash equilibrium in duopoly.

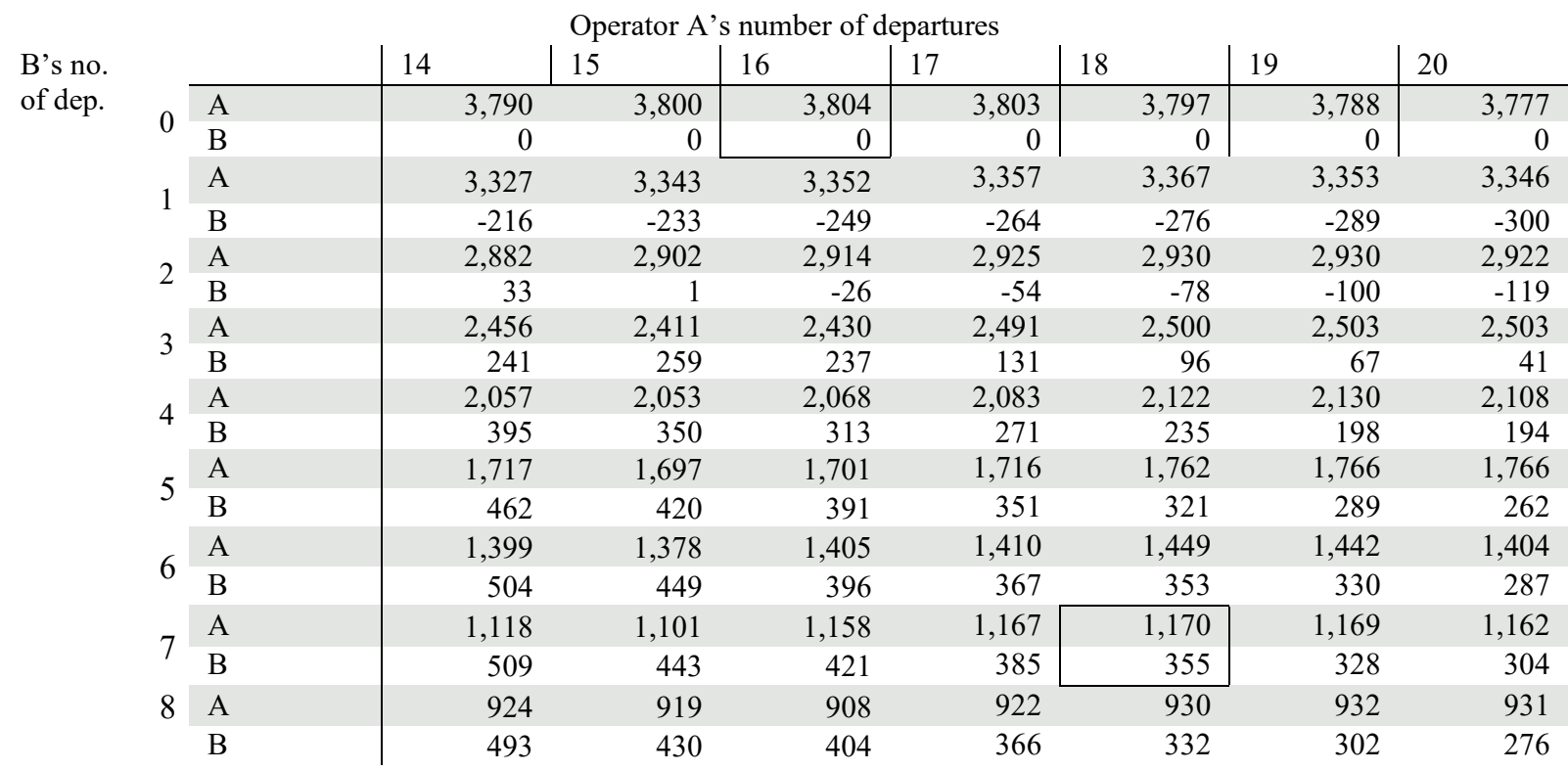

The Nash equilibrium in frequencies is not unique, however, as there are two equilibria which are symmetric in respect to each other: if operator A running X trains and operator B running $Y$ trains is a Nash equilibrium, then operator A running $\mathrm{Y}$ trains and operator $\mathrm{B}$ running $\mathrm{X}$ trains is also a Nash equilibrium, since operators are indistinguishable in our model setup. As we shall see, $\mathrm{X}$ is generally not equal to $\mathrm{Y}$ in Nash equilibrium ${ }^{13}$; we will let A refer to the operator with the higher frequency and B to that with the lower.) Results from the simulation model are shown in Table 2, compared with the two benchmark monopoly situations from section 4.1.

Figure 1 shows fares, demand and profits in Nash equilibrium. One operator has 18 departures and the other has 7. Note that the total number of departures is higher in the duopoly case than in the welfare maximising monopoly ( 25 departures rather than 22) in the base case. The intuition for this is that although a higher frequency generates value for travellers through reduced scheduling costs, it also requires fares to rise in order to pay for the extra trains, and the fare increase is larger than the scheduling cost reduction. The welfare maximum thus has fewer departures. Competing firms, on the other hand, need many departures in order to sustain their market share.

On most departures, operator B offers lower fares and consequently attracts more passengers per departure; it makes a higher profit per departure than A. Departures controlled by A have higher fares and lower profits on average. In particular, those of A's departures which have other operator A departures on either side have the highest fares, lowest demand and yield the lowest profit. In fact, the profit of these departures would increase if

\footnotetext{
13 The model does not guarantee that there is a unique equilibrium (i.e. a single pair of symmetric equilibria). Pathological case can be constructed with more (pairs of) equilibria, but they are rare. In the simulation experiments presented here, equilibria are unique.
} 
fares were lowered - but most of the attracted demand would come from other departures controlled by A, so A's total profit would decrease. This shows how the overall outcome is affected by a market setup where operators are able to control the fare of each individual departure, and maximises the aggregate profit from all their departures, rather than the profit of each departure seen in isolation. This is also why it matters greatly how the departures of different operators are ordered, as we shall see in section 4.3.

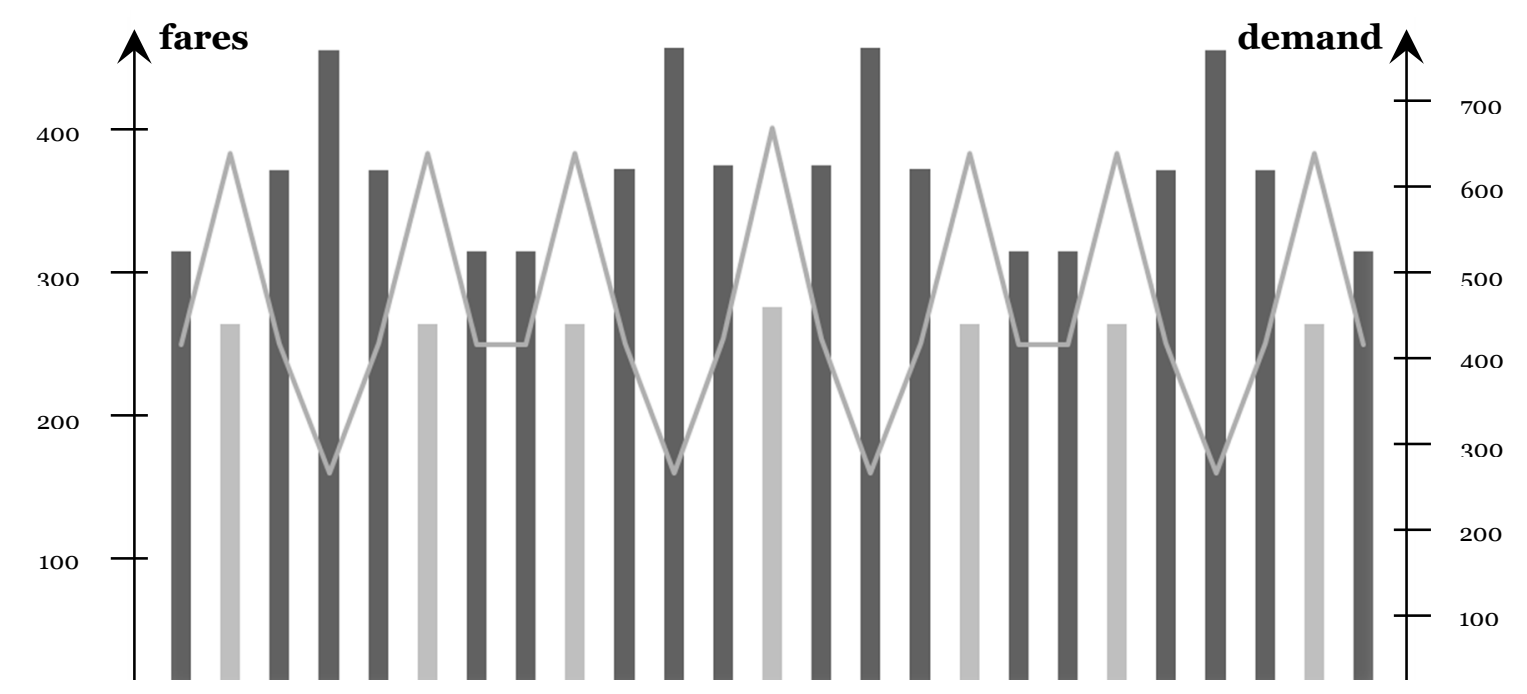

Figure 1. Fares (bars, left-hand scale) and demand (line, right-hand scale) in Nash equilibrium. Operator A's fares are dark grey; B's fares light grey.

The operators' ability to control fares individually for each departure, and to take into account whether a departure competes with other departures controlled by the same operator or those of a competitor, is also the reason why the Nash equilibrium is asymmetric in frequencies, with one "large" operator running many departures and one "small" operator running few. Remember that the operators in the model setup are identical, and that there are no economies of scale in production costs in the model (apart from a fixed cost to enter the market at all). Given this, one might expect that the operators should offer the same frequency in equilibrium, but this is not what happens. Instead, one operator runs a larger number of departures than the other. The frequency equilibrium is thus asymmetric, i.e. the operators' frequencies are different from one another in equilibrium. The appearance of asymmetry of frequencies despite symmetric preconditions is analogous to the results of a simulation of the airline market made by Schipper et al (2007).

The asymmetric frequency equilibrium is a consequence of operators having an incentive to lower their exposure to price competition. When operators have the same number of departures, all departures will be adjacent to departures controlled by a competitor. In contrast, if an operator has more departures than the other, a quasimonopoly situation arises for some of its departures. When three consecutive departures are controlled by the same operator, the one in the middle is shielded from price competition (see Figure 1). In effect, every additional departure that the dominating operator (operator A) adds will have this feature, creating an incentive for it to increase its frequency further.

The smaller operator B, by contrast, lacks such incentives. An operator with few departures will face a situation where any additional departure will face full price competition, and hence work to lower the general price level on the market. The 'marginal departure' is hence less profitable for the smaller operator, giving it an incentive to keep its number of departures low.

Of course, it is only profitable for the larger operator to add more departures up to a point. With more departures, the average profit per departure falls, because of declining average demand per departure. Even when an extra departure is profitable on its own, it induces losses on existing departures by attracting demand from them. This induced loss of new departures affects the larger operator the most. At some point, the induced loss will be greater than the profit of the extra departure, even if that departure is shielded from price competition. For this reason, one operator does not end up running all departures.

The pattern that the bigger operator in a passenger rail duopoly charges higher fares is confirmed by empirical studies from Italy (Bergantino et al, 2015; Beria et al., 2016), the Czech Republic (Tomeš et al, 2014; Tomeš et al, 2016) and Sweden (Vigren, 2017). The emergence of one "high cost" operator with high fares, low occupancy rates and many departures, and one "low cost" operator with low fares, high occupancy rates and few departures, is hence unavoidable despite identical operators (in terms of production costs), no scale economies and no user 
heterogeneity. An outside viewer might draw the conclusion that the "low-cost" operator is in some sense more efficient than the "high-cost" operator - but this would be a misinterpretation of what causes the outcome.

In reality, economies of scale in the number of services will benefit a larger operator (Wheat \& Smith, 2015) and increase the frequency asymmetry further. Similarly, a long-standing good reputation among customers by an incumbent operator might allow it to charge higher fares and thus become more profitable than its competitor, as suggested by Fröidh \& Byström (2013) and Ruiz-Rúa \& Palacín (2013), also enhancing the frequency asymmetry.

Table 2 shows the profits, given Nash prices, for operator A and B for various combinations of frequencies, with profit maximising monopoly (16:0) and Nash equilibrium duopoly (18:7) marked. The Nash equilibrium is A's best option on that row and B's best option in that column; hence neither of them can increase their profit by unilaterally changing their frequency.

The two competing operators run 25 trains per day between them, compared to 22 in the welfare maximising benchmark (see Table 3), while average fares are roughly three times higher and consumer surplus $30 \%$ lower. Aggregate welfare is $13 \%$ lower in duopoly compared to welfare maximum. This compares favourably to the welfare loss of $30 \%$ of profit maximising monopoly, compared to the welfare maximum. This welfare gain constitutes the main argument for introducing open access competition on passenger railway lines. Put differently, a competitive duopoly increases overall welfare by $24 \%$ compared to a profit maximising monopoly, with much lower profits and higher consumer surplus (which confirms the detailed calculations on an incumbent operator facing competition made by Johnson \& Nash (2012)).

Table 3. Duopoly under Nash equilibrium, compared to two monopoly situations

\begin{tabular}{lrrr}
\hline & $\begin{array}{r}\text { Welfare max., } \\
\text { no subsidy }\end{array}$ & Profit max. & $\begin{array}{r}\text { Duopoly, } \\
\text { Nash eq. }\end{array}$ \\
\hline $\begin{array}{l}\text { No. of } \\
\text { departures }\end{array}$ & 22 & 16 & $18+7$ \\
$\begin{array}{l}\text { Average } \\
\text { fare }\end{array}$ & 104 & 703 & 317 \\
$\begin{array}{l}\text { No. of } \\
\text { passengers }\end{array}$ & 13,300 & 7,100 & 11,100 \\
$\begin{array}{l}\text { Consumer } \\
\text { surplus }\end{array}$ & $8,840,000$ & $2,430,000$ & $6,190,000$ \\
$\begin{array}{l}\text { Producer } \\
\text { surplus } \\
\text { Total } \\
\text { welfare }\end{array}$ & 0 & $3,800,000$ & $1,520,000$ \\
\hline
\end{tabular}

These results can be compared to those of a standard Cournot duopoly model with linear demand and a single homogenous good, which can be solved analytically (see Appendix A). In that model, social welfare is $11 \%$ lower in duopoly compared to welfare maximising monopoly, while social welfare in a profit maximising monopoly is $25 \%$ lower $^{14}$. Total quantity is $33 \%$ lower in duopoly than in welfare maximum, while it is $50 \%$ lower in profit maximising monopoly. The simulation model predicts $17 \%$ fewer trips in duopoly than in welfare maximum, and $47 \%$ fewer trips in profit maximising monopoly. The effects predicted by the simulation model are thus similar to those from the standard Cournot model, despite the additional complexities in the model reflecting the particularities of open access railway markets.

So far in our analysis, we have made the conventional assumption that operator profits are somehow returned to society at large, for example through corporate taxes and shareholder dividends. We will now look at where the profits are going. Under a regulated monopoly, the sole operator is often a government owned company and its profits hence accrue to the state and ultimately to taxpayers. But under a competitive regime, operators may be private and foreign owned. From the point of view of the citizens in a country, profits may hence be "lost" when they accrue to foreign companies rather than the government or domestically owned companies. It is therefore interesting to see how total welfare (consumer surplus and profits) under monopoly compares with consumer surplus (i.e. excluding profits) in duopoly. In our simulation, consumer surplus in the duopoly is almost exactly the same $(0.7 \%$ lower $)$ as the total welfare in profit maximising monopoly. This implies that if profits are transferred abroad following deregulation, the domestic welfare gain of replacing a monopoly with open access competition vanishes.

\footnotetext{
${ }^{14}$ Appendix A also includes the case of a 'bad' operator with higher marginal cost entering the market. Welfare remains lower than or near the monopoly outcome.
} 
We now make another change in our assumptions. Up to now, the welfare gain of 1 SEK in government revenue has been equal to that of 1 SEK in private revenue, but since government revenue may be used to replace distortionary taxes they should arguably be marked up with the marginal cost of public funds (MCPF). We now compare the welfare in a situation where the government owns a profit maximising monopolist and uses the proceeds to replace distortionary taxes, with the consumer surplus (the 'domestic welfare') in a situation with two foreign owned, competing operators. With $\mathrm{MCPF}=1.3$ (Ministry of Finance, 2010) ${ }^{15}$, the consumer surplus in duopoly is then $16 \%$ lower than welfare under monopoly. This shows that a duopoly with foreign owned operators is not necessarily more efficient than a profit maximising, government owned monopoly, from a domestic point of view.

If operator capacity (the number of trains) is relatively expensive and inflexible, it is possible that one operator will choose a different frequency from what is implied by the Nash equilibrium in order to force its competitor into a position more favourable to itself, under the logic of a Stackelberg game. For some parameter values, though not in the base case, the Stackelberg equilibrium ${ }^{16}$ is different from the Nash equilibrium. Sensitivity analyses show that the Stackelberg equilibria in our model tend to have fewer departures, higher profits, higher fares and lower welfare compared to the Nash equilibrium. This is not typical; Stackelberg games often result in more competitive outcomes than Nash games do (see e.g. Maskin \& Tirole (1987)). The special characteristics of the Stackelberg equilibrium in this paper is an effect of the asymmetry of frequencies described above. When operator A offers fewer departures, the two operators move toward symmetry in frequency space, thus (temporarily) increasing competition and reducing profits. Operator B's best response is to move away from symmetry, i.e. to decrease its own frequency as well.

\subsection{Ordering and timing of departures}

As mentioned above, we assume that operators only decide frequencies while the infrastructure manager decides precise departure times, i.e. the ordering and timing of departures, and we assume that the infrastructure manager strives to maximise aggregate social welfare. This is obviously a simplification of reality, but it reflects the fact that under open access competition, operators cannot freely choose departure times: they apply for capacity and the infrastructure manager (which is normally a government agency) determines how to construct a feasible timetable out of operators' (possibly competing) requests. The timing and ordering of departures have a substantial impact on demand, fares and overall welfare. If the objective of the regulator is to maximise social welfare, we will demonstrate that the regulator should spread departures in accordance with underlying demand patterns (e.g. uniformly given a uniform PDT distribution) and aim for maximal competition between operators by mixing departures by different operators. The intuition is that this minimises the local quasi-monopoly power that arises whenever the same operator controls adjacent departures.

Table 4. Welfare effect of clustering rather than intermingling departures (uniform demand)

\begin{tabular}{lrr} 
& $\begin{array}{c}\text { Intermingled } \\
\text { (A-B-A-A-B-A) }\end{array}$ & \multicolumn{1}{c}{$\begin{array}{c}\text { Clustered } \\
\text { (A-A-B-B-A-A) }\end{array}$} \\
\hline Average & 499 & 559 \\
fare & & $(+12.0 \%)$ \\
No. of & 7,489 & 6,886 \\
passengers & & $(-8.1 \%)$ \\
Consumer & $2,910,000$ & $2,480,000$ \\
surplus & & $(-14.8 \%)$ \\
Producer & $2,000,000$ & $2,110,000$ \\
surplus & & $(+5.6 \%)$ \\
Total & $4,910,000$ & $4,590,000$ \\
welfare & & $(-6.5 \%)$ \\
\hline
\end{tabular}

Table 4 illustrates how the ordering of departures affects results by comparing two ways to organise a situation where one operator has four departures and the other has two: one that is maximally intermingled and one with clusters of departures run by the same operator. The timetable with intermingled departures yields higher total welfare. As expected, this is driven by an intensified price competition that decreases fares, increases demand and improves consumer surplus while lowering profits, compared to the clustered scenario.

\footnotetext{
${ }^{15}$ This value is also used in Swedish CBA guidelines (Trafikverket, 2018)

${ }^{16}$ In a Stackelberg game the independent variables are normally quantity and price; here they are frequency and price.
} 
Table 5. Effects of unevenly spread departures. One departure at a time is moved backward in time $1 / 3$ of the distance to the nearest departure.

\begin{tabular}{lrrrrrrr}
\hline & \multirow{2}{*}{ Baseline } & $\begin{array}{c}\text { Move } \\
\text { dep. 1 (A) }\end{array}$ & $\begin{array}{c}\text { Move } \\
\text { dep. 2 (B) }\end{array}$ & $\begin{array}{c}\text { Move } \\
\text { dep. 3 (A) }\end{array}$ & $\begin{array}{c}\text { Move } \\
\text { dep. 4 (A) }\end{array}$ & $\begin{array}{c}\text { Move } \\
\text { dep. 5 (B) }\end{array}$ & $\begin{array}{c}\text { Move } \\
\text { dep. 6 (A) }\end{array}$ \\
\hline Average & 499 & 486 & 495 & 491 & 499 & 495 & 490 \\
fare & & $(-2.7 \%)$ & $(-0.9 \%)$ & $(-1.6 \%)$ & $(-0.1 \%)$ & $(-0.8 \%)$ & $(-1.9 \%)$ \\
No. of & 7,489 & 6,900 & 7,438 & 7,467 & 7,410 & 7,438 & 7,442 \\
passengers & & $(-7.9 \%)$ & $(-0.7 \%)$ & $(-0.3 \%)$ & $(-1.1 \%)$ & $(-0.7 \%)$ & $(-0.6 \%)$ \\
Consumer & $2,910,000$ & $3,040,000$ & $2,950,000$ & $2,980,000$ & $2,910,000$ & $2,950,000$ & $2,990,000$ \\
surplus & & $(+4.4 \%)$ & $(+1.2 \%)$ & $(+2.3 \%)$ & $(-0.1 \%)$ & $(+1.2 \%)$ & $(+2.7 \%)$ \\
Producer & $2,000,000$ & $1,610,000$ & $1,940,000$ & $1,930,000$ & $1,950,000$ & $1,940,000$ & $1,900,000$ \\
surplus & & $(-19.4 \%)$ & $(-2.9 \%)$ & $(-3.5 \%)$ & $(-2.3 \%)$ & $(-2.9 \%)$ & $(-4.7 \%)$ \\
Total & $4,910,000$ & $4,650,000$ & $4,890,000$ & $4,910,000$ & $4,860,000$ & $4,890,000$ & $4,890,000$ \\
welfare & & $(-5.3 \%)$ & $(-0.5 \%)$ & $(+0.0 \%)$ & $(-1.0 \%)$ & $(-0.5 \%)$ & $(-0.3 \%)$ \\
\hline
\end{tabular}

The case for evenly distributed departures is illustrated in Table 5, which shows the welfare effects of changing departure times slightly. One departure at a time is then moved backward in time (to the left, in relation to the departures in Table 5) 1/3 of the time-distance to the nearest departure. The table shows the effect on aggregate welfare of each change, compared to the base case where departures are spread evenly. It is noticeable that any deviation from the situation where departures are spread evenly reduces total welfare. In this case, however, the welfare loss is due to decreases in producer surplus, whereas consumer surplus tends to rise somewhat when departures are less evenly spread, as this increases price competition. Note also that the welfare effect is usually small. This implies that if there are practical reasons for spreading departures unevenly the 'cost' of doing so is manageable.

An important question is to what extent these results from clustering and unevenly spread departures are products of the simulation model's uniform PDT distribution (as described in Section 3.4). To test this, consider a triangular potential demand curve that rises linearly in the first half of the period, then falls linearly to zero in the second half. Using this demand curve, the difference between intermingled and clustered departures is studied for the same number of departures and for the same values of $\alpha, \beta, K$ and $\kappa$ as before. As seen in Table 6 , the relative changes are similar to those of the flat-demand case for all examined indicators: producers with clustered departures are able to increase fares compared to the 'intermingled' case, which leads to higher profits in spite of lower ridership, with total welfare declining.

Table 6. Welfare effect of clustering rather than intermingling departures for triangular potential demand

\begin{tabular}{l|rr} 
& $\begin{array}{r}\text { Intermingled } \\
\text { (A-B-A-A-B-A) }\end{array}$ & \multicolumn{1}{c}{$\begin{array}{c}\text { Clustered } \\
\text { (A-A-B-B-A-A) }\end{array}$} \\
\hline Average & 631 & 659 \\
fare & & $(+4.3 \%)$ \\
No. of & 7,422 & 7,174 \\
passengers & & $(-3.3 \%)$ \\
Consumer & $3,630,000$ & $3,330,000$ \\
surplus & & $(-8.3 \%)$ \\
Producer & $2,950,000$ & $2,990,000$ \\
surplus & & $(+1.4 \%)$ \\
Total & $6,570,000$ & $6,310,000$ \\
welfare & & $(-4.0 \%)$ \\
\hline
\end{tabular}

As to the spacing of departures, it is not evident how the infrastructure manager should do this to maximise welfare if the PDF distribution is triangular. A natural starting point is to space departures so they have the same potential demand. With a triangular potential demand from $t=0$ to $t=2$ and a peak at $t=1$, this means that departure times should be $T_{n}=\frac{\sqrt{n}+\sqrt{n-1}}{2 \sqrt{N}}$. This does not maximise welfare, however, once there are competing operators and departure-specific fares. Determining departure time spacing to maximise welfare, conditional on a later fare-setting stage, is a bi-level optimisation problem that cannot be solved analytically. It is feasible to solve using standard optimisation packages, however (we used MS Excel Solver), provided that the problem is 
formulated in a suitable way (this is presented in Appendix D).

The outcomes of four studied scenarios are shown in Table 7: intermingled (A-B-A-A-B-A) and clustered (AA-B-B-A-A) departures, combined with departure time spacing that is either determined to have the same potential demand or optimised to maximise welfare. The fares shown are the Nash equilibria with two profit maximising competing operators. As the period is symmetric, only the first half, i.e. [0,1] is shown. All four scenarios have more departures when demand is highest, near the end of the interval. Still, the 'equal potential demand' scenarios seem to underestimate the value of placing departures close to peak demand. The results confirm that clustering of departures leads to higher average fares, fewer passengers, higher profits, and lower total welfare compared to intermingled departures.

Table 7. Outcomes with triangular potential demand

\begin{tabular}{|c|c|c|c|c|}
\hline & \multicolumn{2}{|c|}{ Equal potential demand } & \multicolumn{2}{|c|}{ Welfare maximising } \\
\hline & Intermingled & Clustered & Intermingled & Clustered \\
\hline Dep. 1 & 0.20 & 0.20 & 0.63 & 0.65 \\
\hline Dep. 2 & 0.49 & 0.49 & 0.72 & 0.73 \\
\hline Dep. 3 & 0.64 & 0.64 & 0.79 & 0.81 \\
\hline Dep. 4 & 0.76 & 0.76 & 0.85 & 0.87 \\
\hline Dep. 5 & 0.86 & 0.86 & 0.92 & 0.93 \\
\hline Dep. 6 & 0.96 & 0.96 & 0.97 & 0.98 \\
\hline Average fare & baseline & $+5.0 \%$ & $+21.8 \%$ & $+37.8 \%$ \\
\hline No. of passengers & baseline & $-4.2 \%$ & $+6.1 \%$ & $-3.1 \%$ \\
\hline Consumer surplus & baseline & $-9.1 \%$ & $+27.1 \%$ & $+8.8 \%$ \\
\hline Producer surplus & baseline & $+0.8 \%$ & $+7.9 \%$ & $+10.1 \%$ \\
\hline Total welfare & baseline & $-3.1 \%$ & $+15.5 \%$ & $+9.6 \%$ \\
\hline
\end{tabular}

The algorithm used here to find the welfare maximising spacing of departures assumes that the infrastructure manager has full information about profits and consumer surplus. In reality, at least the former may be difficult to observe. To optimise timetables, it is still advisable that the infrastructure manager calculates indicators of welfare as precisely as possible. Most likely, this will improve welfare compared to the case where operators choose departure times freely.

\subsection{Incentives to restore monopoly}

The combined profits in a competitive oligopoly market is lower than the profits a monopolist would have. This implies that there are incentives to restore monopoly. Since the combined producer surplus is lower in duopoly Nash equilibrium than under monopoly, there exists a price for the departure slots held by one operator such that, if the other operator bought the slots for that price, both operators would be better off. This means that if trade with departure slots is allowed, monopoly is the likely consequence. 


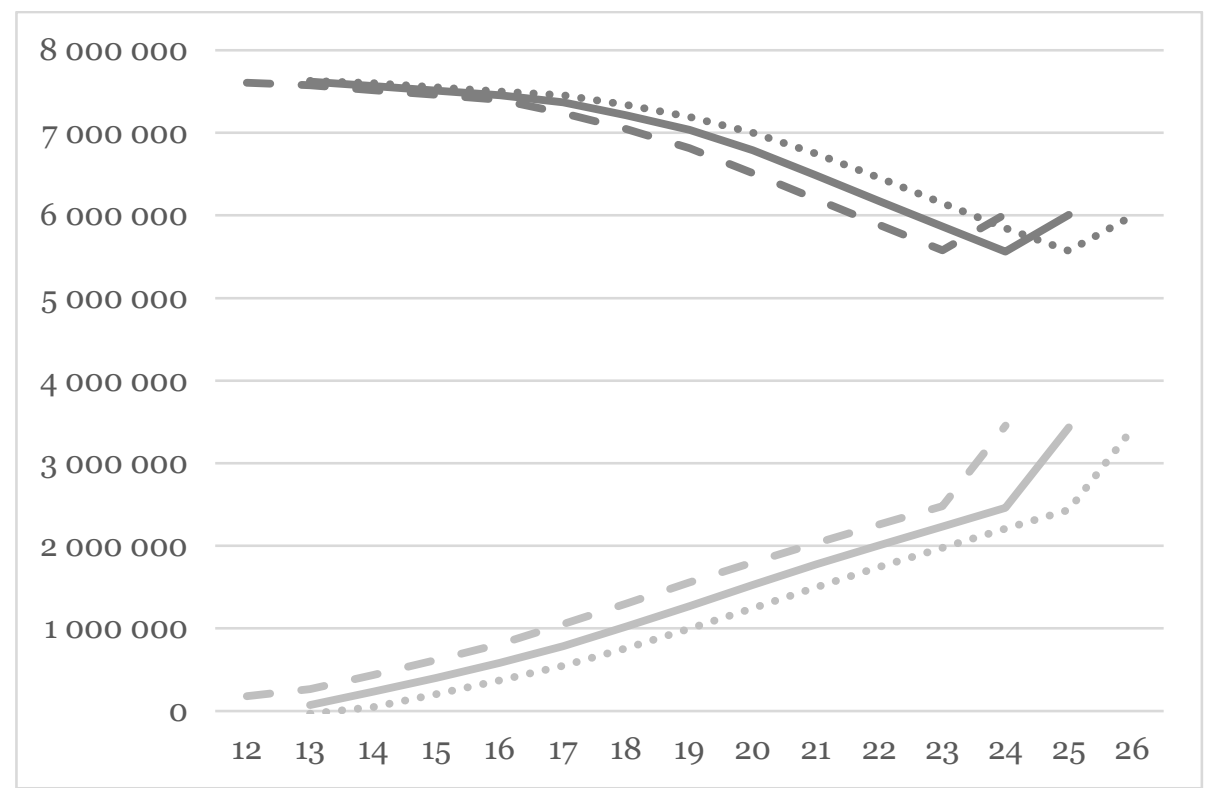

Figure 2. Producer surplus (light grey) and welfare (dark grey) by number of departures held by the larger operator (x-axis) when total number of departures fixed at 24 (dashed lines), 25 (solid lines) or 26 (dotted lines).

Moreover, already a marginal increase in market concentration leads to higher producer surplus. Given that the total number of departures is held constant, the total producer surplus increases with the number of departure slots held by the larger operator (see Figure 2). This means that the smaller operator has an incentive to sell slots to the larger operator: since the total producer surplus increases, there is a slot price which will make both operators better off. This trade will reduce overall welfare, however. The effects are considerable: each slot trade increases combined producer surplus with $36 \%$ on average but reduces overall welfare by $1.9 \%$ on average, indicating that there is also a substantial transfer of benefits from passengers to operators. A similar effect is related to exact departure times: both clustering and timing of departures affect overall welfare (these topics are discussed in section 4.3.)

It is common that operators negotiate and agree among themselves on the details of timetabling issues, including the ordering and timing, and occasionally the number of departures. This is true also for direct competitors. In fact, cooperation between operators to resolve conflicts is part of the formal timetabling process in many countries, including Belgium, France, Germany, the Netherlands, Sweden and Switzerland (Ait Ali \& Eliasson, 2019). The reason for this is practical and originates in the complexity of railway traffic. Staff schedules, rolling stock circulation, connections between different lines and the overall feasibility of the timetable all put constraints on what can be done.

Coordination between operators is not only common today, but is also likely to remain common in the future. Many researchers have suggested slot auctions as a more efficient way to allocate capacity (see e.g. (Borndörfer et al., 2006; Nilsson, 2002; Perennes, 2014)). But if timetables are drawn 'automatically' through an auction, some type of trading or exchange of access slots may need to be permitted in order to assure that operators have enough rolling stock and staff at the right time and place to make the timetable feasible.

Encouraging of coordination is thus likely to remain common, despite the incentives for operators to use this possibility to increase market concentration. This has a negative welfare effect. Both clustering of departures and market concentration tends to increase producer surplus but decrease overall welfare, while spreading departures unevenly lowers both producer surplus and overall welfare.

\section{Implications for market regulation policy}

Our simulation results show that going from monopoly to open access competition tends to increase social welfare substantially, reducing profits and benefitting travellers. Indeed, total welfare in the duopoly situation is close to the ideal, hypothetical case with a welfare maximising operator under a cost recovery constraint. These results are analogous to those of a standard Cournot model, despite the additional complexities of railway markets - a natural "product differentiation" in time, different prices for different "goods" (departures), and a regulator deciding the ordering and spacing of departures. Our simulation results do not include possible productivity improvements due to increased internal efficiency, though we note that a study by Casullo (2016) that tried to find such effects failed to do so. 
There is a stable equilibrium with two operators, conditional on that they cannot restore monopoly through merging or buying each other's departure slots. The outcome is asymmetric in terms of fares and frequency of service, even when the two operators are identical and there are no economies of scale or taste heterogeneity: an equilibrium with one "low-cost" operator (low fares, high occupancy, low frequency) and one "high-cost" operator (vice versa) emerges naturally from the model. The asymmetry is driven by incentives to avoid the most competitive situation, where travellers have two options to choose from almost regardless of their preferred departure time, as this brings down fares and profitability. This asymmetric frequency equilibrium lowers total welfare compared to symmetry.

Because of the same incentives, welfare decreases if operators are allowed to coordinate and negotiate freely to resolve conflicts. Doing so would give them a chance to arrange departures to limit competition, bringing fares up and ridership down. Slots should not be allowed to change hands, because of incentives to increase market concentration or even reinstate monopoly. A welfare maximising infrastructure agency should arrange operators' departures so that they are intermingled, in order to increase price competition.

The default assumption is that all of the producer surplus is included in the social welfare. However, this assumption is not innocuous. In practice, monopolies often consist of a government owned company, meaning that profits accrue to taxpayers, while under duopoly, at least some operators may be foreign owned. Hence, a national policy maker may well consider profits accruing to foreign shareholders as "lost" from a domestic perspective. It should be stressed that railway markets are different from standard product markets since there is only physical room for a limited number of producers, and each departure time presents a certain monopoly power. This means that even in the long run and under the assumption that the railway market is otherwise perfect, firms will make a profit, which can be substantial. This contrasts with standard product markets where long-run profits can reasonably be assumed to be zero when capital costs etc. are taken into account. This means that the question of to whom profits accrue is not moot. If operators' profits are regarded as "lost" in the duopoly situation, this tends to cancel out most of the increase in social welfare in the simulations (although the precise loss depends on parameter values). It is therefore worth asking whether there are policies or regulations that recoup at least some of operators' profits to the government (and hence the taxpayer collective), for instance higher infrastructure charges.

Another significant problem is the fact that the combined profits of the operators are always lower than the profit of a monopolist. This means that operators have an incentive to restore the monopoly situation, for example by merging or colluding, or by one operator buying the other's departure slots (if this is allowed). The increased profit will be more than enough to compensate the competing operator. In fact, the producer surplus always increases when the larger operator takes over a departure slot from the smaller operator if the total number of departures is held constant. Hence, if departure slots can be traded, or if operators can merge or buy each other, the competitive situation is not stable but will revert to monopoly. The fundamental reason for this is that for any fixed time period, there is a finite number of departure slots, so the number of possible entrants is limited in any given time-period. There is hence a commercial incentive for one operator to buy or somehow gain control of all the slots to become a monopolist. Once an operator has control over all departure slots, the monopolist may choose not to use all of them.

Constructing a procedural framework that prevents this outcome is not trivial. One countermeasure is to forbid operators to trade departure slots with each other. But such a ban may not be enough: negotiations and some amount of quid-pro-quo between operators is usually a necessary part of timetable construction in reality. Moreover, tacit collusion between operators to divide submarkets between them may be very difficult to prevent in practice.

This observation also poses a significant problem for procedures aiming to allocate scarce capacity through market mechanisms, such as auctions or scarcity pricing. Since the profits of a monopolist is higher than the combined profits of two competing operators, a would-be monopolist will always be willing to outbid its competitors. Hence, it is highly likely that a capacity allocation (with a finite number of departure slots) based on operators' willingness-to-pay will result in a monopoly situation - with the welfare losses highlighted above.

We have used our model to study a number of policy proposals to counteract the problems above. However, several of them have in fact turned out to be either ineffective or counter-productive and have therefore not been included in the above proposal. These include measures to curb excessive operator profits and to force the frequency equilibrium toward symmetry.

First, consider the case to curb excessive profit. In a duopoly market, competition is less than perfect, and operators' profits do not decrease toward zero, as discussed above. Policy makers may therefore wish to tax those earnings. One option to their disposal is to raise infrastructure charges. We have looked at the effects of a flat fee per departure of 20,000 SEK per year (raising the cost per departure with 50\% compared to the base case). This reduces the number of departures by $20 \%$, raises fares, reduces ridership, and lowers welfare (see Table 8 ). The welfare loss is almost entirely due to a decrease in consumer surplus, indicating that high access charges is an ineffective tool for curbing excessive profit. 


\begin{tabular}{lrr}
\hline & $\begin{array}{r}\text { Duopoly, } \\
\text { base case }\end{array}$ & $\begin{array}{r}\text { Duopoly, high } \\
\text { access charges }\end{array}$ \\
\hline No. of departures & $18+7$ & $14+6$ \\
Average fare & 317 & 346 \\
No. of passengers & 11,100 & 10,700 \\
Consumer surplus & $6,190,000$ & $5,720,000$ \\
Producer surplus & $1,520,000$ & $1,500,000$ \\
Extra access charges & nil & 400,000 \\
Total welfare & $7,720,000$ & $7,620,000$ \\
\hline
\end{tabular}

This shows the problem with raising infrastructure charges to curb profit: in order to succeed, it must amount to a substantial increase in the cost per departure, thus altering the incentives of the frequency game. Therefore, the equilibrium switches to a point with fewer departures and higher fares, resulting in a welfare loss that is well above what the government earns from the charge increase. This inefficiency of infrastructure charges above marginal costs and externalities is unsurprising. In fact, it holds generally that it is optimal to operate an economy at the production-possibilities frontier, implying that intermediary goods - including infrastructure - should not be taxed. Diamond and Mirrlees (1971) show that this result generally holds even in the presence of distortionary taxation.

Now consider the frequency equilibrium. While the above policy recommendations are shown to result in asymmetric frequency equilibrium, the welfare maximising frequency combination under price competition is symmetric. It would be better for society if operators could be made to offer an equal number of departures, unless the means to make such outcome come about is so inefficient that it cancels out the advantage. This turns out to be the case; a number of policies designed to produce equally many departures end up either failing through not providing sufficient incentives for the smaller operator to raise frequency, or damaging total welfare by lowering combined frequency or raising average fares.

One possibility is for the infrastructure agency to decline requests for capacity beyond a certain point in order to reduce the frequency of the larger operator. However, this is in effect similar to forcing the larger operator to pursue a Stackelberg strategy (described in section 4.2). According to the logic of asymmetric frequency equilibria, the smaller operator then has an incentive to also decrease its frequency, contrary to the regulator's intentions. Fares increase, ridership falls and consumer surplus decreases because of the policy. Profits may increase under such a scheme, but not enough to keep social welfare from falling.

Another possibility is to have rules that force operators to have a certain minimum frequency. The dynamics of the price game is unaffected by this. However, the regulating agency may not know what frequency is optimal, since it lacks information needed to calculate the value of individual departures, such as ridership and fares. In addition, forcing operators to run more departures than they had planned for may result in a service of poor quality, or not be feasible at all because of the long lead-times and large financial obligations associated with acquiring rolling stock and scaling up operations.

Yet another option is to skew incentives to make the offering of equally many departures seem more attractive to operators. The regulator might even abstain from trying to maximise competition, in cases where the competitors offer close to equal frequencies. Instead, it can bundle the smaller operator's departures closer together, thus easing the price pressure there. The priority should be to lessen the burden on the smaller operator while preserving the pressure on the larger operator as much as possible, in order to force a new Nash equilibrium with lower combined profits compared to the previous equilibrium point.

The problem with this idea is that while the larger operator seems to gain from a reordering of departures to lessen price competition, the smaller operator does not. (In the 'clustered' example in Section 4.3, the profit of the smaller operator falls by almost a percentage point while that of the larger operator increases by over $6 \%$, compared to the base case.) The intuition for this is that without drastic changes, departures belonging to the smaller operator will continue to lie close to the larger operator's departures. For the larger operator, in contrast, its existing shielded pseudo-monopoly areas can easily be expanded. Simulations confirm that any changes large enough to have a positive impact on the behaviour of the smaller operator will increase average fares enough to make the welfare effect of the policy negative.

Yet another idea is to vary access charges according to the number of departures that an operator runs. It seems however that this will not work without dramatic variations that are probably unfeasible due to practicality and fairness reasons. 


\section{Conclusions}

Traditionally, most railway markets have been monopolies. There are different types of railway monopolies, for example public utilities, vertically integrated commercial firms, commercial firms that operate under a concession and commercial firms that uphold a monopoly position in an unregulated environment. These various regimes correspond to different objective functions for the operator, such as welfare maximisation with some constraints (e.g. on net profit), pure profit maximisation, or profit maximisation under an entry deterrence strategy. Tendered traffic resembles either government run services or profit maximising monopoly and thus does not need to be modelled explicitly.

Open access competition has the potential to increase overall welfare by reducing the deadweight losses stemming from monopoly situations. Our simulation model demonstrates that there exists a stable equilibrium with two operators, where both operators make positive profits. The duopoly situation benefits travellers at the expense of operators, compared to profit maximising monopoly. Total welfare increases substantially (around 24\% in our simulations) and is in fact close to unsubsidised welfare maximum. These basic results are analogous to a standard Cournot model, but our simulations demonstrate that they are valid also in a market such as open access passenger railways, with a natural "product differentiation" in time, different prices for different "goods" (departures), and a regulator deciding the ordering and spacing of departures striving to maximise welfare.

These particularities of railway markets, reflected in our model, also lead to a number of results differing from the simple standard model. Duopoly equilibria are asymmetric, with one operator offering higher frequency and higher average fares than the other, even assuming two identical operators with no economies of scale. This stems from operators' ability to set individual fares for each departure, taking into account whether a departure competes with other departures controlled by the same operator or those of a competitor.

Even the mere threat of competition may increase welfare despite of a profit maximising monopoly. The entry deterrence scenario leads to higher frequency compared to pure profit maximising monopoly, generating a small positive welfare contribution. Forcing a monopolist to increase its frequency is not an effective strategy to increase welfare, however, as long as the operator is free so set monopoly fares.

If the market resembles a Stackelberg game rather than a Nash equilibrium, some results change. Sensitivity analyses show that the Stackelberg equilibria in our model tend to have fewer departures, higher profits and higher fares compared to the Nash equilibrium. This differs from the standard case, where Stackelberg games usually result in more competitive outcomes than Nash games do.

From a domestic point of view, ownership of operators matters greatly for the conclusions. Going from a government owned, profit maximising monopoly to a competitive duopoly where operators' profits accrue to foreign shareholders, domestic welfare may very well decrease, despite the fact that global welfare increases, since this overall increase in welfare to a large extent may be transferred abroad through operator profits.

The timing and ordering of departures affect social welfare. A welfare maximising infrastructure manager should use its regulatory power to ensure a high level of price competition by placing competing operators' departures adjacent to each other, rather than letting a departure enjoy a local monopoly in time by surrounding it with departures by the same operator. This gives travellers options to choose from throughout the day, thus increasing competition. Departures should also be spread evenly rather than lumped together, with consideration taken to the underlying demand pattern, but this requirement is aligned with operators' incentives and may hence demand less attention from regulators.

From this it follows that letting operators coordinate and negotiate freely to resolve conflicts will tend to decrease welfare, since this gives them a chance to arrange departures in a way that limits competition, bringing fares and profits up and ridership down.

A significant problem is the fact that the producer surplus is always lower than the profit of a monopolist. This means that operators have an incentive to restore the monopoly situation, for example by merging or colluding, or by one operator buying the other's departure slots if slot trading is allowed. Even a marginal increase in market concentration leads to higher producer surplus but lower total welfare. The source of this problem is ultimately that there is a finite number of profitable departure slots, because of fixed costs per departure. This result appears even without economies of scale in production. In reality, such economies exist and will tend to reinforce this problem.

Preventing monopolies to emerge is not trivial: negotiations between operators is usually a necessary part of timetable construction. This result also poses a significant problem for willingness-to-pay based capacity allocation mechanisms, such as auctions or scarcity pricing. Since the profits of a monopolist is higher than the combined profits of two competing operators, a would-be monopolist will be willing to outbid its competitors. Regulating service frequency is ineffective as a means to increase welfare when fares are set freely.

In all, our results show that open access competition has the potential of substantial welfare improvements compared to monopoly situations. However, they also show that the market regulation framework, ownership of operators and the capacity allocation process matters greatly for the outcome. It is hence important that 
governments and infrastructure managers analyse and design such regulations and processes carefully in order for these potential benefits to materialise.

\section{Acknowledgements}

Funding from the Swedish Transport Administration is gratefully acknowledged. We have benefited from fruitful discussions with Abderrahman Ait-Ali, Martin Aronsson, Chris Nash, Andrew Smith and Victoria Svedberg. 


\section{Appendix A. Cournot duopoly}

Assume two identical producers 1 and 2 who produce quantities $q_{1}$ and $q_{2}$ with the same marginal production cost $c$. The inverse demand function is $p=a-b q$ where $q=q_{1}+q_{2}$. Producer $k$ 's profit is hence $\pi_{k}=$ $(p-c) q_{k}$, the consumer surplus is $C S=\frac{(a-p) q}{2}$, and the total welfare is

$$
W=\pi_{1}+\pi_{2}+C S=(p-2 c+a) \frac{q}{2}
$$

The welfare maximum $W^{*}$ is given by

$$
\begin{aligned}
\frac{d W}{d q}=(a-c)-b q & =0 \rightarrow q=\frac{a-c}{b} ; p=c \\
W^{*} & =\frac{(a-c)^{2}}{2 b}
\end{aligned}
$$

This can be compared with the market equilibrium, given by the conditions

$$
k=1,2: \quad \frac{d \pi_{k}}{d q_{k}}=\frac{d p}{d q_{k}} q_{k}+(p-c)=0 \rightarrow q_{1}=q_{2}=\frac{p-c}{b} ; q_{1} b+c=p
$$

Plugging this into the inverse demand function gives the market equilibrium price $p=\frac{a+2 c}{3}$ and the market equilibrium welfare $W^{\prime}=\frac{4(a-c)^{2}}{9 b}$. The ratio between market welfare $W^{\prime}$ and maximal welfare $W^{*}$ is hence $8 / 9$, and the ratio between the corresponding quantities is $2 / 3$.

The monopoly situation with only producer 1 is given by the condition

$$
\frac{d \pi_{1}}{d q}=-b q_{1}+p-c=0 \rightarrow q_{1}=\frac{a-c}{2 b} ; p=\frac{a+c}{2}
$$

Which gives the welfare $W^{\prime \prime}=\frac{3(a-c)^{2}}{8 b}$. The ratio between monopoly welfare and maximal welfare is hence $3 / 4$, and the ratio between the corresponding quantities is $1 / 2$.

Competition will increase welfare compared to monopoly even when the entrant is actually less efficient than the incumbent. Assume that producer 2 has higher marginal production cost than producer $1: c_{2}>c_{1}$. (Assume further that $c_{2} \leq \frac{a+c_{1}}{2}$ and $c_{2} \leq a-2 c_{1}$; this guarantees that all quantities are positive.) Straightforward calculations then give that the ratio between total welfare under monopoly held by producer 1 and total welfare under competition is

$$
\frac{27\left(a-c_{1}\right)^{2}}{4\left(10\left(a-c_{1}\right)\left(a-c_{2}\right)-\left(a-c_{1}\right)^{2}-\left(a-c_{2}\right)^{2}+12\left(c_{1}-c_{2}\right)^{2}\right)}
$$

When producers are identical $\left(c_{1}=c_{2}\right)$, this ratio is $\frac{27}{32} \approx 0.84$, but it is less than 1 also when $c_{2}>c_{1}$ as long as the difference is not too big. This means that even a new producer entering a former monopoly market will increase welfare, even if its production costs are higher than the former monopolist's, since this reduces the monopolist's market power. 


\section{Appendix B. Calculating consumer surplus}

Use the equation

$$
D(t)=\varphi(t)-\beta c(t)
$$

Solve for the generalised cost:

$$
c(t)=\frac{\varphi(t)-D(t)}{\beta}
$$

For a given PDT $t$, the consumer surplus is the triangular area

$$
\begin{gathered}
\boldsymbol{C S}(\boldsymbol{t})=\frac{\mathbf{1}}{\mathbf{2}} \boldsymbol{D}(\boldsymbol{t})\left(\frac{\boldsymbol{\varphi}(\boldsymbol{t})}{\boldsymbol{\beta}}-\frac{\boldsymbol{\varphi}(\boldsymbol{t})-\boldsymbol{D}(\boldsymbol{t})}{\boldsymbol{\beta}}\right)=\frac{\boldsymbol{D}(\boldsymbol{t})^{2}}{\mathbf{2} \boldsymbol{\beta}}= \\
=\frac{1}{2 \beta}(\varphi-\beta c(t))^{2}=\frac{\varphi^{2}}{2 \beta}+\frac{\beta}{2} c(t)^{2}-\varphi c(t)= \\
=\frac{\varphi^{2}}{2 \beta}+\frac{\beta}{2}\left(p_{n}+\alpha\left|T_{n}-t\right|\right)^{2}-\varphi\left(p_{n}+\alpha\left|T_{n}-t\right|\right)= \\
=\frac{\varphi^{2}}{2 \beta}+\frac{\beta}{2} p_{n}^{2}+\frac{\alpha^{2} \beta}{2}\left(T_{n}-t\right)^{2}+\alpha \beta p_{n}\left|T_{n}-t\right|-\varphi p_{n}-\varphi \alpha\left|T_{n}-t\right|= \\
=\frac{\varphi^{2}+\beta^{2} p_{n}^{2}-2 \varphi \beta p_{n}}{2 \beta}+\frac{\alpha^{2} \beta}{2}\left(T_{n}-t\right)^{2}+\alpha\left(\beta p_{n}-\varphi\right)\left|T_{n}-t\right|= \\
=\frac{1}{2 \beta}\left(\varphi-\beta p_{n}\right)^{2}+\frac{\alpha^{2} \beta}{2}\left(T_{n}-t\right)^{2}+\alpha\left(\beta p_{n}-\varphi\right)\left|T_{n}-t\right|
\end{gathered}
$$

Integrate over $\left[\tau_{n}, \tau_{n+1}\right]$ assuming $\varphi(t)$ is constant (as in the simulation):

$$
\begin{aligned}
C S_{n}=\frac{\left(\varphi-\beta p_{n}\right)^{2}}{2 \beta} & \int_{\tau_{n}}^{\tau_{n+1}} d t+\frac{\alpha^{2} \beta}{2} \int_{\tau_{n}}^{\tau_{n+1}}\left(T_{n}-t\right)^{2} d t+\alpha\left(\beta p_{n}-\varphi\right) \int_{\tau_{n}}^{T_{n}}\left(T_{n}-t\right) d t \\
& +\alpha\left(\beta p_{n}-\varphi\right) \int_{T_{n}}^{\tau_{n+1}}\left(t-T_{n}\right) d t \\
& =\frac{\left(\varphi-\beta p_{n}\right)^{2}}{2 \beta}\left(\tau_{n+1}-\tau_{n}\right)+\frac{\alpha^{2} \beta}{6}\left(\left(T_{n}-\tau_{n}\right)^{3}+\left(\tau_{n+1}-T_{n}\right)^{3}\right) \\
& +\frac{\alpha\left(\beta p_{n}-\varphi\right)}{2}\left(\left(T_{n}-\tau_{n}\right)^{2}+\left(\tau_{n+1}-T_{n}\right)^{2}\right)
\end{aligned}
$$




\section{Appendix C. Calculating demand}

As before,

$$
\tau_{n}=\frac{p_{n+1}-p_{n}}{2 \alpha}+\frac{T_{n+1}+T_{n}}{2}, n=1, \ldots, N-1
$$

Assuming a uniform PDT distribution, i.e. that $\varphi(t)$ is constant, total demand becomes

$$
\begin{aligned}
D & =\sum_{n}\left\{\int_{0}^{T_{n}-\tau_{n}}\left(\varphi-\beta\left(\alpha \mathrm{t}+p_{n}\right)\right) d \mathrm{t}+\int_{0}^{\tau_{n+1}-T_{n}}\left(\varphi-\beta\left(\alpha \mathrm{t}+p_{n}\right)\right) d \mathrm{t}\right\} \\
& =\sum_{n}\left\{\left(\varphi-\beta p_{n}\right)\left(\tau_{n+1}-\tau_{n}\right)-\frac{\alpha \beta}{2}\left(\left(T_{n}-\tau_{n}\right)^{2}+\left(\tau_{n+1}-T_{n}\right)^{2}\right)\right\}
\end{aligned}
$$

If the PDT increases or decreases linearly, as in a triangular PDT distribution (i.e. $\varphi(t)=q t$ for some constant $q)$, total demand becomes

$$
\begin{aligned}
D= & \sum_{n}\left\{\int_{0}^{T_{n}-\tau_{n}}\left(q t-\beta\left(\alpha \mathrm{t}+p_{n}\right)\right) d \mathrm{t}+\int_{0}^{\tau_{n+1}-T_{n}}\left(q t-\beta\left(\alpha \mathrm{t}+p_{n}\right)\right) d \mathrm{t}\right\} \\
& =\sum_{n}\left\{\frac{q-\alpha \beta}{2}\left(\left(T_{n}-\tau_{n}\right)^{2}+\left(\tau_{n+1}-T_{n}\right)^{2}\right)-\beta p_{n}\left(\tau_{n+1}-\tau_{n}\right)\right\}
\end{aligned}
$$




\section{Appendix D. Optimal spread of departures with triangular shaped demand}

Assume that the PDT distribution $\varphi(t)$ is triangular on the interval [0,2] with a peak at 1 (see figure).

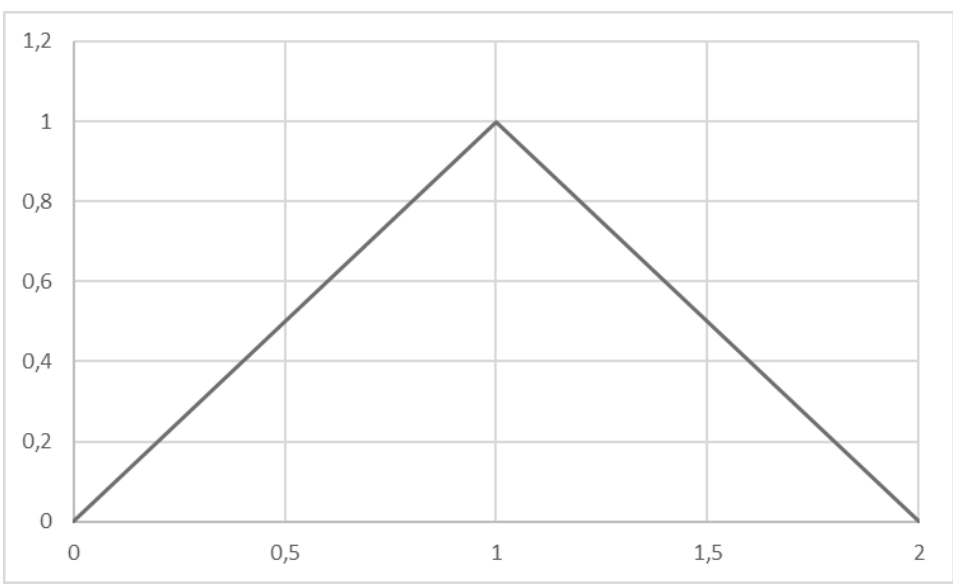

Assume also that the departures before and after $\mathrm{t}=1$ are symmetrical with respect to departure times, fares and which operator runs the departure. Then it is sufficient to study the interval $[0,1]$, so we have that $\varphi(t)=t$. Denote the departures $n=1, \ldots, N$, corresponding departure times $T_{n}$ and fares $p_{n}$. We also define $T_{0}=0$ and $T_{N+1}=1$. The generalised cost of a potential passenger with PDT $t$ is

$$
c(t)=\min _{\mathrm{n}}\left(p_{n}+\alpha\left|T_{n}-t\right|\right)
$$

We will now define the cut-off points between departures that determine, depending on a passenger's PDT, which departure is most favourable. This will include a mechanism to deal with the fact that the cut-off point may lie further away than the nearest departure.

Consider a time $t$ in $\left[T_{n}, T_{n+1}\right]$. Define the lowest generalised costs ahead of $t$ and after $t$, respectively, as

$$
\begin{gathered}
a_{n}=\min _{\mathrm{k} \leq \mathrm{n}}\left(p_{k}-\alpha T_{k}\right) \quad n=1, \ldots, N \\
b_{n}=\min _{\mathrm{k} \geq \mathrm{n}+1}\left(p_{k}+\alpha T_{k}\right) \quad n=0, \ldots, N-1
\end{gathered}
$$

Then let

$$
\tau_{n}=\max \left(T_{n}, \min \left(T_{n+1}, \frac{b_{n}-a_{n}}{2 \alpha}\right)\right)
$$

This splits the interval $\left[T_{n}, T_{n+1}\right]$ in two parts: $\left[T_{n}, \tau_{n}\right]$ and $\left[\tau_{n}, T_{n+1}\right]$. If $\frac{b_{n}-a_{n}}{2 \alpha}$ is in $\left[T_{n}, T_{n+1}\right]$ it is separated in two nonzero parts. If $\frac{b_{n}-a_{n}}{2 \alpha}$ is not in $\left[T_{n}, T_{n+1}\right]$ the first part of the interval is 0 and the other part constitutes the whole interval, or vice versa.

The generalised cost can now be expressed on the two parts of $\left[T_{n}, T_{n+1}\right]$ as

$$
\begin{array}{ll}
T_{n} \leq t \leq \tau_{n}: & c(t)=\min _{\mathrm{k} \leq \mathrm{n}} p_{k}+\alpha\left(t-T_{k}\right)=\alpha t+\min _{\mathrm{k} \leq \mathrm{n}}\left(p_{k}-\alpha T_{k}\right)=\alpha t+a_{n} \\
\tau_{n} \leq t \leq T_{n+1}: & c(t)=\min _{\mathrm{k} \geq \mathrm{n}+1} p_{k}+\alpha\left(T_{k}-t\right)=-\alpha t+\min _{\mathrm{k} \geq \mathrm{n}+1}\left(p_{k}+\alpha T_{k}\right)=-\alpha t+b_{n}
\end{array}
$$

Let $\tau_{0}=0, \tau_{N}=1$. The demand at $t$ is $D(t)=\max \{\varphi(t)-\beta c(t), 0\}$. We will now rewrite this expression to deal with the discontinuity in 0 . Using the expressions for $c(t)$ above, $D(t) \geq 0$ gives us that

$$
\begin{array}{ll}
T_{n} \leq t \leq \tau_{n}: & \varphi(t)-\beta\left(\alpha t+a_{n}\right) \geq 0 \rightarrow t \leq \frac{-\beta a_{n}}{\alpha \beta-1} \text { om } \alpha \beta>1 ; \text { if } \alpha \beta<1 \text { this condition is always } \\
& \text { satisfied } \\
\tau_{n} \leq t \leq T_{n+1}: & \varphi(t)-\beta\left(-\alpha t+b_{n}\right) \geq 0 \rightarrow t \geq \frac{\beta b_{n}}{1+\alpha \beta}
\end{array}
$$

We can now write the cut-off points as

$$
\tau_{n}^{-}=\max \left(T_{n}, \min \left(\frac{-\beta a_{n}}{\alpha \beta-1}, \tau_{n}\right)\right)
$$




$$
\tau_{n}^{+}=\min \left(T_{n+1}, \max \left(\frac{\beta b_{n}}{\alpha \beta+1}, \tau_{n}\right)\right)
$$

and demand on the interval $\left[T_{n}, T_{n+1}\right]$ can be rewritten as

$$
\begin{array}{ll}
T_{n} \leq t \leq \tau_{n}^{-}: & D(t)=\varphi(t)-\beta\left(\alpha t+a_{n}\right)=t-\beta\left(\alpha t+a_{n}\right)=(1-\alpha \beta) t-\beta a_{n} \\
\tau_{n}^{+} \leq t \leq T_{n+1}: & D(t)=\varphi(t)-\beta\left(-\alpha t+b_{n}\right)=t-\beta\left(-\alpha t+b_{n}\right)=(1+\alpha \beta) t-\beta b_{n}
\end{array}
$$

We integrate to get the total demand on the interval:

$$
\begin{gathered}
D=\int_{T_{n}}^{\tau_{n}^{-}}(1-\alpha \beta) t-\beta a_{n}+\int_{\tau_{n}^{+}}^{T_{n+1}}(1+\alpha \beta) t-\beta b_{n}= \\
=\frac{(1-\alpha \beta)}{2}\left(\tau_{n}^{-2}-T_{n}^{2}\right)-\beta a_{n}\left(\tau_{n}^{-}-T_{n}\right)+\frac{(1+\alpha \beta)}{2}\left(T_{n+1}^{2}-\tau_{n}^{+2}\right)-\beta b_{n}\left(T_{n+1}-\tau_{n}^{+}\right)
\end{gathered}
$$

To calculate the producer surplus $P S$ we first define the fares on the interval as

$$
\begin{aligned}
& p_{n}^{-}=p_{k^{*}} \quad \text { where } k^{*}=\underset{\mathrm{k} \leq \mathrm{n}}{\operatorname{argmin}}\left(p_{k}-\alpha T_{k}\right) \quad n=1, \ldots, N \\
& p_{n}^{+}=p_{k^{*}} \quad \text { where } k^{*}=\underset{\mathrm{k} \geq \mathrm{n}+1}{\operatorname{argmin}}\left(p_{k}+\alpha T_{k}\right) \quad n=0, \ldots, N-1
\end{aligned}
$$

The producer surplus is then

$$
P S=\left[\frac{(1-\alpha \beta)}{2}\left(\tau_{n}^{-2}-T_{n}^{2}\right)-\beta a_{n}\left(\tau_{n}^{-}-T_{n}\right)\right] p_{n}^{-}+\left[\frac{(1+\alpha \beta)}{2}\left(T_{n+1}^{2}-\tau_{n}^{+2}\right)-\beta b_{n}\left(T_{n+1}-\tau_{n}^{+}\right)\right] p_{n}^{+}
$$

The consumer surplus $C S$ at $t$ is

$$
\begin{array}{ll}
T_{n} \leq t \leq \tau_{n}^{-}: & \operatorname{CS}(t)=\frac{1}{2 \beta} D(t)^{2}=\frac{1}{2 \beta}\left((1-\alpha \beta) t-\beta a_{n}\right)^{2} \\
\tau_{n}^{+} \leq t \leq T_{n+1}: & \operatorname{CS}(t)=\frac{1}{2 \beta} D(t)^{2}=\frac{1}{2 \beta}\left((1+\alpha \beta) t-\beta b_{n}\right)^{2}
\end{array}
$$

Integration gives us

$$
\begin{gathered}
\frac{1}{2 \beta} \int_{T_{n}}^{\tau_{n}^{-}}\left((1-\alpha \beta) t-\beta a_{n}\right)^{2}+\frac{1}{2 \beta} \int_{\tau_{n}^{+}}^{T_{n+1}}\left((1+\alpha \beta) t-\beta b_{n}\right)^{2}= \\
\frac{1}{6 \beta}\left[\frac{\left((1-\alpha \beta) \tau_{n}^{-}-\beta a_{n}\right)^{3}}{1-\alpha \beta}-\frac{\left((1-\alpha \beta) T_{n}-\beta a_{n}\right)^{3}}{1-\alpha \beta}+\frac{\left((1+\alpha \beta) T_{n+1}-\beta b_{n}\right)^{3}}{1+\alpha \beta}-\frac{\left((1+\alpha \beta) \tau_{n}^{+}-\beta b_{n}\right)^{3}}{1+\alpha \beta}\right]
\end{gathered}
$$


Robustness tests have been conducted by varying the parameters $\alpha, \beta$ and $\kappa$. Each variable has been multiplied by a coefficient of 1.5 , and 0.5 relative to the base case. The table below presents the key results. The relative welfare differences between the welfare maximising benchmark, profit maximising monopoly and Nash equilibrium duopoly are quite stable over a range of parameter values. Changes in demand are also stable, while the change in service frequency (number of departures) varies more and fares vary much more, especially when varying the demand/price elasticity (which is expected).

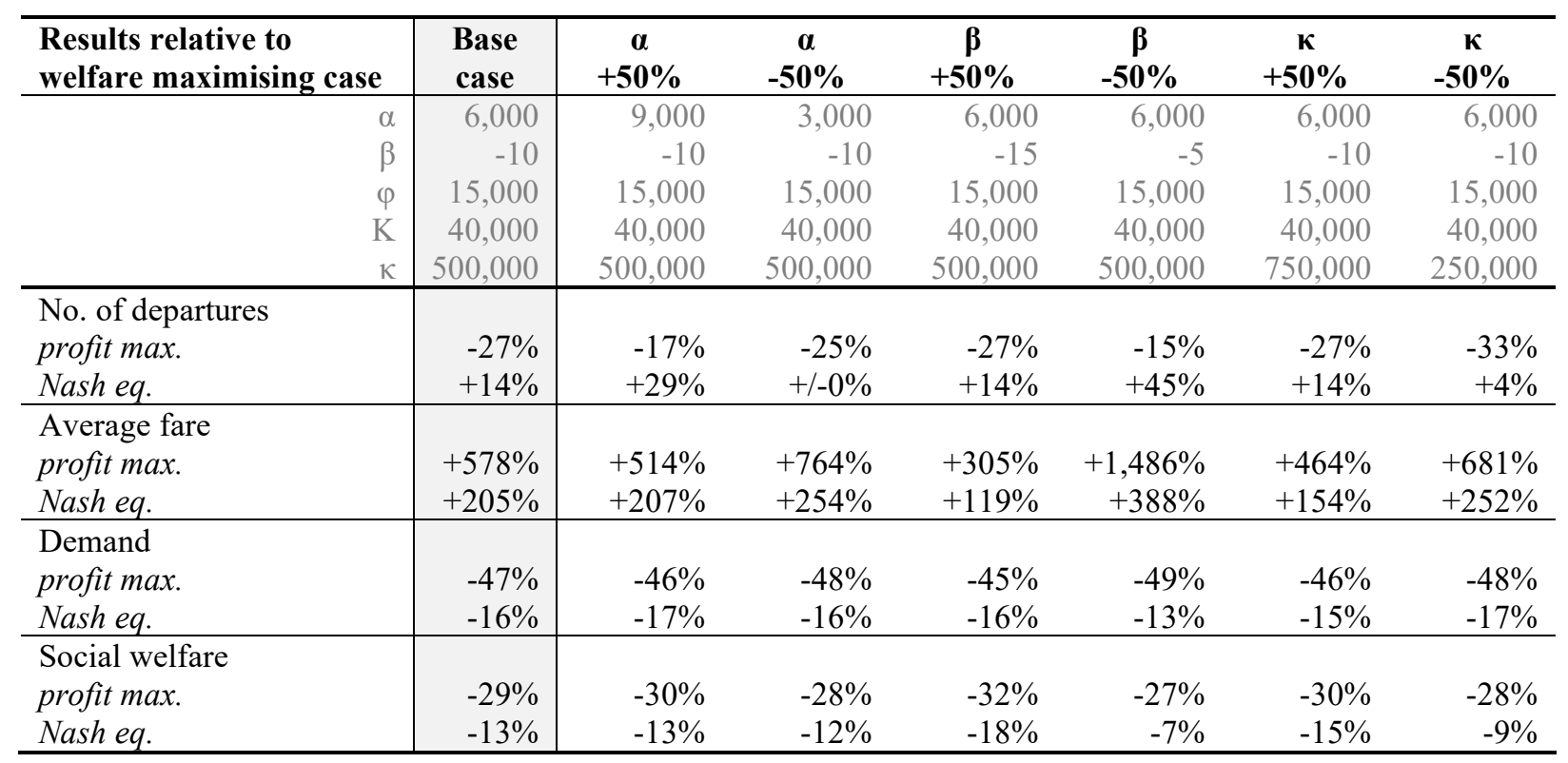

The number of departures is consistently lower under profit maximisation and higher under competition compared to welfare maximum. Fares are highest under profit maximising monopoly and lowest in the welfare maximising case. For demand and social welfare, the opposite is true; both measures are highest in welfare maximum and lowest under profit maximising monopoly.

When the scheduling cost $\alpha$ is raised the number of departures increases relatively more under competition than in the other scenarios. An interpretation is that when passengers place relatively higher importance on the schedule delay then on the fare, operators in a competitive situation are quickest to respond.

Concerning fares, a profit maximising monopolist reacts more strongly to changes in $\alpha$ compared to the other scenarios; raising fares when the scheduling cost is low and lowering fares when the scheduling cost is high. The reason for this is that $\alpha$ takes away from travellers' willingness to pay, and when $\alpha$ drops the monopolist is better at exploiting this. Differences in demand and social welfare between the three regimes are stable with respect to $\alpha$.

When the demand elasticity $\beta$ is lowered, it is welfare efficient to run fewer services. The tendency to do so is however less strong in the duopoly case, as operators need to keep many departures to retain market share in the face of competition. The ratio of number of departures in Nash equilibrium to that in welfare maximum hence increases for low values of $\beta$.

Low values of $\beta$ make it easier to raise fares without losing passengers. This is something that commercial operators, especially profit maximising monopolists, take more advantage of than a welfare maximiser. On the other hand, a low $\beta$ lowers travellers' generalised cost, all else being equal. This counteracts the effect of raised prises, but on balance demand under a profit maximising regime falls even further behind the welfare maximising benchmark when $\beta$ is low. In Nash equilibrium, the equivalent gap decreases somewhat.

Changes in demand elasticity $\beta$ have implications for the relative welfare outcome of different regimes. Most pointedly, the welfare outcome of competition comes closer to welfare maximum when $\beta$ decreases. Driving this change is both increasing frequency of service in the competitive equilibrium and the fact that demand is less responsive to high fares, so is more equal under the two regimes.

Larger values for the cost per day $\kappa$ increase economies of scale (apart from increasing cost), which is why this parameter affects the number of departures for a welfare maximiser and, to a smaller extent, a profit maximiser. The competitive Nash equilibrium is not affected by changes to $\kappa$ however, and hence neither is the frequency asymmetry. But changes to the cost per departure $\mathrm{K}$ do affect frequencies under competition, with an increase of $50 \%$ compared to the base case reduces the larger operator's number of departures from 18 to 14 and the smaller operator's from seven to six, i.e. a proportionately larger change for the large operator. Smaller values for $K$ 
increase frequencies in a similar pattern. A combination of higher $\kappa$ and lower $K$ (a proxy for economies of scale) hence increases the degree of asymmetry in service frequency, as expected.

Fares under the three regimes are more equal when $\kappa$ is large and less equal when it is small. The intuition behind this is that fixed cost constitutes a higher proportion of a welfare maximiser's fares (remember that we maximise welfare under a non-negative profit constraint), and so has more impact on its level. Demand is stable with respect to $\kappa$. The welfare gap between duopoly competition and welfare maximum decreases for small $\kappa$, as a consequence of more similar frequency of service. 


\section{References}

Ait Ali, A., \& Eliasson, J. (2019). Railway capacity allocation: a survey of market organizations, allocation processes and track access charges (Working Paper No. 2019:1). Swedish National Road \& Transport Research Institute (VTI), Stockholm.

Alexandersson, G., \& Hultén, S. (2008). The Swedish Railway Deregulation Path. Review of Network Economics, 7(1), 18-36.

Alexandersson, G., \& Hultén, S. (2009). The complexity of market structure-prospects for on-the-track competition in Sweden 1. Presented at the 11th conference on competition and ownership in land passenger transport, Delft.

Bergantino, A. S., Capozza, C., \& Capurso, M. (2015). The impact of open access on intra- and inter-modal rail competition. A national level analysis in Italy. Transport Policy, 39, 77-86.

Beria, P., Redondi, R., \& Malighetti, P. (2016). The effect of open access competition on average rail prices. The case of Milan - Ancona. Journal of Rail Transport Planning \& Management, 6(3), 271-283.

Borndörfer, R., Grötschel, M., Lukac, S., Mitusch, K., Schlechte, T., Schultz, S., \& Tanner, A. (2006). An Auctioning Approach to Railway Slot Allocation. Competition and Regulation in Network Industries, $1(2), 163-196$.

Broman, E., \& Eliasson, J. (2017). Market dynamics in on-rail competition. Transportation Research Procedia, $22,232-244$.

Casullo, L. (2016). The efficiency impact of open access competition in rail markets: The case of domestic passenger services in Europe (International Transport Forum Discussion Paper 2016-07). OECD, Paris.

Diamond, P. A., \& Mirrlees, J. A. (1971). Optimal Taxation and Public Production I: Production Efficiency. The American Economic Review, 61(1), 8-27.

Eliasson, J., \& Börjesson, M. (2014). On timetable assumptions in railway investment appraisal. Transport Policy, 36, 118-126.

Evans, A. (1987). A Theoretical Comparison of Competition with Other Economic Regimes for Bus Services. Journal of Transport Economics and Policy, 21(1), 7-36.

Evans, A. (1990). Competition and the Structure of Local Bus Markets. Journal of Transport Economics and Policy, 24(3), 255-281.

Fröidh, O., \& Byström, C. (2013). Competition on the tracks - Passengers' response to deregulation of interregional rail services. Transportation Research Part A: Policy and Practice, 56, 1-10.

Johnson, D., \& Nash, C. (2012). Competition and the provision of rail passenger services: A simulation exercise. Journal of Rail Transport Planning \& Management, 2(1), 14-22.

Maskin, E., \& Tirole, J. (1987). A theory of dynamic oligopoly, III: Cournot competition. European Economic Review, 31(4), 947-968.

Ministry of Finance (2010). Swedish Tax Policy: Recent Trends and Future Challenges (Report to the Expert Group on Public Economics No. 2010:4). Ministry of Finance, Stockholm.

Nilsson, J.-E. (2002). Towards a welfare enhancing process to manage railway infrastructure access. Transportation Research Part A: Policy and Practice, 36(5), 419-436.

Perennes, P. (2014). Use of combinatorial auctions in the railway industry: Can the "invisible hand" draw the railway timetable? Transportation Research Part A: Policy and Practice, 67, 175-187. 
Preston, J. (2008). Competition in transit markets. Research in Transportation Economics, 23(1), 75-84.

Ruiz-Rúa, A., \& Palacín, R. (2013). Towards a liberalised European high speed railway sector: Analysis and modelling of competition using Game Theory. European Transport Research Review, 5(1), 53-63.

Schipper, Y., Nijkamp, P., \& Rietveld, P. (2007). Deregulation and welfare in airline markets: An analysis of frequency equilibria. European Journal of Operational Research, 178(1), 194-206.

SIKA (2009). Värden och metoder för transportsektorns samhällsekonomiska analyser (SIKA Rapport No. 2009:3). SIKA, Stockholm.

Tomeš, Z., Kvizda, M., Jandová, M., \& Rederer, V. (2016). Open access passenger rail competition in the Czech Republic. Transport Policy, 47, 203-211.

Tomeš, Z., Kvizda, M., Nigrin, T., \& Seidenglanz, D. (2014). Competition in the railway passenger market in the Czech Republic. Research in Transportation Economics, 48, 270-276.

Trafikverket (2018). Analysmetod och samhällsekonomiska kalkylvärden för transportsektorn (ASEK No. 6.1). Trafikverket, Borlänge.

Vigren, A. (2017). Competition in Swedish passenger railway: Entry in an open access market and its effect on prices. Economics of Transportation, 11-12, 49-59.

Wheat, P., \& Smith, A. S. J. (2015). Do the Usual Results of Railway Returns to Scale and Density Hold in the Case of Heterogeneity in Outputs? A Hedonic Cost Function Approach. Journal of Transport Economics and Policy, 49(1), 35-47.

WSP (2010). Trafikanters värdering av tid - den nationella tidsvärdestudien 2007/08 (WSP rapport No. 2010:11). WSP, Stockholm. 